\title{
Direitos Sexuais e reprodutivos: uma crítica ao Artigo 14 do Protocolo dos Direitos das Mulheres da África ${ }^{(*)}$
}

\author{
REPRODUCTIVE AND SEXUAL RIGHTS: A CRITIQUE OF ARTICLE \\ 14 OF THE PROTOCOL ON THE RIGHTS OF WOMEN IN AFRICA
}

Harriet Diana Musoke $e^{(*)}$

\begin{abstract}
Queremos direitos reprodutivos para todas as mulheres, independentemente da idade, da cor, classe social, condições fisicas, sexualidade ou estado civil. Podemos ter experiências muito diferentes, o que pode significar que temos necessidades especificas diferentes. Mas, todas nós queremos a mesma coisa - o direito a estruturas adequadas, o direito a decidir sobre como queremos viver nossas vidas como mulheres. ${ }^{I}$
\end{abstract}

\section{RESUMO}

Este artigo aborda os diversos desafios que os países africanos vêm enfrentando na implantação do Protocolo dos Direitos das Mulheres na Carta Africana dos Direitos Humanos, em particular com relação ao Artigo 14, o qual trata dos direitos reprodutivos e sexuais. Discute questões como os direitos das mulheres africanas para definir o número de filhos e o momento em que desejam tê-los, bem como o controle de natalidade e a possibilidade dos Estados de garantir o direito de acesso ao aborto legal. Conclui que, embora o Artigo 14 seja uma mudança bem-vinda, as mulheres na África não podem exercer seus direitos reprodutivos e sexuais livremente, a menos que se levem em consideração as aspirações da comunidade.

(*) Artigo com base em tese de doutorado não publicada, intitulada "Africanização dos direitos reprodutivos e sexuais: A experiência ugandense", Emory University School, Atlanta, Georgia, Estados Unidos.

$\left.{ }^{* *}\right)$ Professora Sênior do Departamento Central de Direito de Kampala; Professora Sênior da Universidade Islâmica. Advogada da Corte Judicial de Uganda. Kampala - Uganda. E-mail: $<$ hmusoke@ hotmail.com>.

Texto recebido em 14.12.10. Aprovado em 01.02.11.

(1) WOMEN'S Health and Information Centre. Disponível em: <http://www.nchealthywomen.org>. Acesso em: 20 fev. 2012. 


\title{
Palavras-chave:
}

Direitos Humanos; Direitos Reprodutivos e Sexuais; Protocolo das Mulheres.

\begin{abstract}
This article discusses the various challenges African states will face during implementation of the African Charter on Human and People Rights on the Rights of Women, in particular Article 14 which guarantees women the right to exercise their reproductive and sexual rights. It discusses if women in Africa have a right to determine the number and spacing of children, if they have a right to fertility control and if the State can ensure to them the right to access legal abortion. The paper finds that, although Article 14 is a welcome move, women in Africa cannot exercise their reproductive and sexual rights freely unless it is done taking into account the community aspirations.
\end{abstract}

\section{Keywords:}

African Women's Protocol; Human Rights; Reproductive and Sexual Health and Rights.

\section{OBJETIVOS}

Os anos 1960 testemunharam o surgimento de uma "nova consciência" com relação aos direitos das mulheres, como direitos humanos, e à necessidade de incrementar a promoção e a proteção destes direitos ${ }^{2}$. Como resultado dessa tomada de consciência, esforços regionais e internacionais têm sido feitos, para tornar estes direitos uma realidade. Em nível regional, o último passo dado foi a adoção do Protocolo dos Direitos das Mulheres na Carta Africana dos Direitos Humanos - o Protocolo das Mulheres ${ }^{3}$, que tem como objetivo assegurar a todas as mulheres africanas o pleno exercício de seus direitos humanos. Para

(2) THE DIVISION for the Advancement of Women. Disponível em: <http://www.un.org/womenwatch/ daw/cedaw $>$. Acesso em: $20 \mathrm{dez} .2006$.

(3) Em dezembro de 2010, 29 países de 53 assinaram e ratificaram o Protocolo das Mulheres. São eles: Angola, Benin, Burkina Faso, Cabo Verde, Gana, Gâmbia, Mali, Mauritânia, Nigéria, Senegal,Ilhas Seychelles, Togo, Tanzânia, Comores, Djibouti, Ruanda, Lesoto, Zâmbia, Moçambique,Namíbia, África do Sul, Malauí, Libia, Uganda, República Democrática do Congo, Camarões, Libéria, Zimbábue e Guiné-Bissau. AFRICAN COMISSION ON HUMAN AND PEOPLE'S RIGHTS.Protocol to the African Charter on Human and Peoples' Rights on the Rights of Women in Africa, 2003. Disponível em: <http://achpr.org/english/_info/women_en.html>. Acesso em: 8 dez. 2010. 
alcançar esta meta, o Protocolo das Mulheres garante, entre outros, o pleno exercício dos direitos reprodutivos e sexuais.

O Protocolo das Mulheres é o primeiro instrumento de direitos humanos a proporcionar explicitamente a garantia dos direitos reprodutivos e sexuais femininos. O documento entrou em vigor em novembro de 2005 e foi festejado pelas mulheres e ativistas em direitos humanos. As africanas têm demonstrado uma grande esperança de que os sistemas de direitos humanos do continente e de cada país promoverão a igualdade de gênero, o respeito aos direitos humanos e a promoção da justiça social com relação ao sexo feminino, incluindo o direito de tomar decisões a respeito de seus corpos. Para as africanas, o Protocolo é "um acontecimento importante na história das lutas femininas na África pelo reconhecimento dos direitos das mulheres" ${ }^{\text {. }}$ O documento é considerado como um guia em direção a "uma nova e significante era em relação à promoção e proteção dos direitos das mulheres na África e o fim da impunidade para todas as formas de violações aos direitos humanos das africanas". ${ }^{5}$

Outros atores, entretanto, saudaram a adoção do Protocolo com mais ceticismo, destacando o histórico negativo por parte das instituições do Estado e da sociedade em lidar com as questões e interesses femininos ${ }^{6}$, para as quais não se dá prioridade em níveis nacionais, regionais ou internacional. Dado o baixo padrão de promoção dos interesses das mulheres, surge o questionamento sobre quão efetivo o Protocolo das Mulheres pode ser na realização dos direitos reprodutivos e sexuais na África.

O objetivo geral deste artigo é debater as diversas mudanças que as nações irão enfrentar para a implantação do Artigo 14 do Protocolo das Mulheres, como, por exemplo, o direito de determinar o número de filhos e o momento de engravidar, o direito ao controle de natalidade e a participação do Estado e da comunidade na garantia do direito de acesso ao aborto legal.

Consideramos que, embora o Artigo seja bem-vindo, ele é excessivamente ambicioso, irreal e não considera as condições específicas das africanas. Em particular, ele ignora deliberadamente a realidade social - o contexto das forças culturais - na qual as mulheres tomam decisões sobre seus corpos, que não são pensadas apenas no nível individual. A linguagem usada no Artigo 14 é vaga e fraca em face dos modelos culturais, e deve ser vista como uma introdução de um conceito estrangeiro e hostil que não é totalmente aceito pelas africanas.

Os direitos reprodutivos e sexuais estão relacionados aos direitos das mulheres e à autonomia e igualdade de gênero. Consideramos que estes direitos

(4) KAFUI, Adjamagbo-Johnson. The entry into force of the Protocol on the Rights of Women in Africa: A Challenge for Africa and Women. Pambazuka News, n. 162, June 24, 2004

(5) WANDIA, Mary. Rights of Women in Africa: Launch of Petition to the African Union. Pambazuka News, n. 159, June 3, 2004.

(6) Id. Ibid. 
são controversos e tratam de temas enraizados na tradição, cultura e religião das sociedades patriarcais conservadoras, as quais usam normas conservadoras para manter o status quo existente, em uma tentativa de preservar leis religiosas e culturais que negam às mulheres sua plena autonomia.

Temos também a falta de detalhamento do Artigo 14, que não mostra claramente como os direitos reprodutivos e sexuais das africanas podem ser melhorados, nem especifica os mecanismos para a execução das responsabilidades dos Estados. Em nossa opinião, não é suficiente a simples adaptação do documento, que impõe obrigações vagas aos Estados-membros de criarem condições para a adoção da legislação. Deve haver mecanismos efetivos para policiar o progresso dos países, caso contrário, os direitos assegurados no Protocolo serão apenas direitos no papel.

\section{INTRODUÇÃO}

Este artigo analisa e critica os termos do Artigo 14 do Protocolo das Mulheres e coloca a questão: como os direitos reprodutivos e sexuais podem ser "africanizados" para assegurar à maioria das africanas seu pleno exercício? Buscamos demonstrar que a ambiguidade no texto do Artigo e seus avanços nos princípios individuais podem tornar sua implantação e aceitação difíceis entre as africanas. Examinamos também os debates que devem acontecer com a implementação desse dispositivo. Analisamos então as provisões individuais do Artigo 14 no contexto da sociedade africana.

Enquanto o Artigo 14 é um marco e os seus elaboradores são elogiados pelo belo trabalho, a questão que permanece é se ele é uma resposta completa aos questionamentos sobre o reconhecimento e realização dos direitos reprodutivos e sexuais na África. Argumentamos que, apesar dos direitos das mulheres serem fortemente defendidos e do documento ser bem-vindo, as provisões do Artigo 14 não são adequadas para assegurar o pleno gozo destes direitos. 0 Artigo aborda os direitos enfatizando a autonomia individual, enquanto a sociedade africana é naturalmente comunitária. Os valores comunitários ditam que as mulheres não vivem isoladas, mas em um ambiente comunitário.

Para o Artigo 14 ter significado, deve haver um conhecimento adequado dos vários contextos nos quais as normas e procedimentos se desenvolveram. Os caminhos que levaram as mulheres africanas até onde elas chegaram hoje também devem ser examinados. Aspectos relevantes do contexto no qual as mulheres operam hoje e no futuro devem ser avaliados em termos das perspectivas dos poderes atuais e da distribuição de forças.

Qualquer nova abordagem a ser proposta deve refletir de maneira realística essas forças e modelos de autoridade, a fim de se tornar um guia de condutas futuras para todos os atores relevantes. Novas abordagens podem ou não ecoar o passado, o que não é essencial para sua efetividade, que depende das 
expectativas atuais da comunidade, de legalidade e praticabilidade. Sugerimos um enfoque híbrido, individual (direitos humanos) e comunitário, que considere, de um lado, os princípios internacionais dos direitos humanos de dignidade, integridade e não discriminação e, de outro, as aspirações da comunidade. $O$ Artigo 14 precisa ser legitimado como uma perspectiva comunitária para ser completamente abraçado por uma grande maioria de mulheres africanas.

Sejam quais forem os argumentos, temos consciência de que as mulheres e as sociedades africanas são diferentes entre si. Assim, as razões apontadas podem ser mais eficazes em uma área do que em outra. Não se podem descartar preconceitos de que algumas africanas têm mais liberdade no exercício de seus direitos do que outras. Perspectivas individuais das mulheres são formatadas por diversas experiências e socializações. Muitas culturas são diferentes, mas todas as africanas sofrem pelos efeitos do colonialismo, pobreza, doenças, analfabetismo e má nutrição. Além disso, a maioria das mulheres na África enfrentam os mesmos valores socioculturais e parâmetros que impactam negativamente sobre seus direitos reprodutivos e sexuais. Os costumes podem, de alguma maneira, diferir de país para país, mas as raízes em crenças culturais e sociais e a pressão para que as mulheres se submetam a estas crenças são as mesmas. Ademais, todas as mulheres na África são afetadas pelo direito consuetudinário, que governa assuntos de reprodução e sexualidade. Embora os países africanos tenham também a tradição do direito civil, a lei dos costumes prevalece. Finalmente, a religião ou os sistemas de crenças têm um importante papel em todos os aspectos da vida, especialmente na reprodução. Os aspectos religiosos estão tão profundamente enraizados na África que foram integrados aos costumes sociais e culturais. Dessa maneira, o comportamento pode ser diferente de uma sociedade para outra, mas os mesmos problemas surgirão no processo de implantação do Artigo 14 do Protocolo das Mulheres.

\section{UMA CRÍTICA AO ARTIGO 14 DO PROTOCOLO DAS MULHERES}

O Protocolo das Mulheres trata das questões relacionadas aos direitos humanos femininos. Alguns de seus objetivos específicos são: evocar a igualdade de gênero nas "constituições nacionais e em outros instrumentos legislativos" dos países signatários ${ }^{7}$; modificar os padrões culturais e sociais que perpetuam a discriminação sexual; ; garantir a segurança física e emocional da mulher, tanto na esfera pública, como na privada ${ }^{9}$; condenar todas as práticas prejudiciais que afetam os direitos humanos fundamentais das mulheres ${ }^{10}$; assegurar que elas gozem de direitos iguais aos de seus parceiros no casamento ${ }^{11}$; permitir que as

\footnotetext{
(7) Protocolo das Mulheres, op. cit., Art. 2(1)(a)

(8) Id. Ibid. 2(2)

(9) Id. Ibid. 4(2)(a)

(10) Id. Ibid. 5

(11) Id. Ibid. 6
} 
mulheres possam se separar ou se divorciar da mesma maneira que os homens; ${ }^{12}$ promover os direitos das mulheres à informação, assistência legal, participação política, educação e treinamento ${ }^{13}$; protegê-las nos conflitos armados ${ }^{14}$; promover seu desenvolvimento profissional ${ }^{15}$; respeitar os direitos reprodutivos e da saúde feminina ${ }^{16}$ e assegurar os direitos das mulheres à herança, a um ambiente saudável e sustentável, ao desenvolvimento sustentável, à alimentação adequada, à moradia e a um contexto cultural positivo ${ }^{17}$. Ele também prevê proteção especial para idosas e mulheres com deficiências ${ }^{18}$.

O direito mais inovador no Protocolo das Mulheres está em seu Artigo 14 que trata dos "Direitos à Saúde e à Reprodução" e que afirma:

1. Os Estados-membros devem assegurar que o direito da mulher à saúde, incluindo a saúde sexual e reprodutiva, seja respeitado e promovido, o que engloba:

a) o direito ao controle da natalidade;

b) o direito de decidir se quer ter filhos, a quantidade de crianças que terá e quando;

c) o direito de escolher qualquer método de contracepção;

d) o direito à autoproteção e a ser protegida contra doenças sexualmente transmissíveis, incluindo a AIDS;

e) o direito de ser informada sobre suas condições de saúde e sobre as condições de saúde do parceiro, particularmente se afetado por doenças sexualmente transmissíveis, incluindo a AIDS, de acordo com os padrões e as melhores práticas internacionais;

f) o direito a ter educação para o planejamento familiar.

2. Os Estados-membros devem tomar todas as medidas apropriadas para:

a) providenciar serviços de saúde adequados e acessíveis, incluindo informação, educação e programas comunitários, para as mulheres, especialmente àquelas que vivem em zonas rurais;

b) implantar e reforçar serviços de saúde e de nutrição no pré-natal, no parto e após o parto, para mulheres grávidas e que estejam amamentando;

c) proteger os direitos reprodutivos das mulheres, autorizando abortos médicos em casos de agressão sexual, estupros, incesto e quando a continuidade da gravidez coloca em risco a saúde física ou mental da mãe, a vida da mãe ou a do feto.

(12) Id. Ibid. 7

(13) Id. Ibid. 8, 9, 12 respectivamente

(14) Id. Ibid. 11

(15) Id. Ibid. 13

(16) Id. Ibid. 14

(17) Id. Ibid. 15, 16, 17, 28, 19, 20 e 21 respectivamente

(18) Id. Ibid. 22 e 23 respectivamente 
Enquanto esses direitos já foram previamente referendados em vários documentos internacionais sobre os direitos humanos, o Artigo introduz duas inovações: primeira, o direito de ser informada sobre suas condições de saúde e sobre as condições de saúde do parceiro, particularmente se afetado por doenças sexualmente transmissíveis, incluindo a AIDS, na cláusula 1(e); e segunda, a proteção às decisões da mulher sobre reprodução, "autorizando abortos médicos em casos de agressão sexual, estupros, incesto e quando a continuidade da gravidez coloca em risco a saúde física ou mental da mãe, a vida da mãe ou a do feto", na cláusula 2(c). Essa é a primeira vez que estes direitos são especificamente garantidos em um instrumento internacionalmente vinculante.

Os direitos assegurados pelo Artigo 14 são bem articulados e muito bem-vindos $\mathrm{e}$, se implementados, poderiam dar à mulher a plena autonomia $\mathrm{e}$ integridade física pelas quais ela tem lutado. A garantia de dignidade, igualdade e liberdade é central para o pleno gozo dos direitos humanos das mulheres. No entanto, enquanto seus objetivos forem difíceis de alcançar, o Artigo 14 pode terminar sendo não mais do que retórico.

Para começar, o Artigo 14 foi redigido na linha "atire primeiro, pergunte depois", em resposta a um fenômeno pouco conhecido, e não atendeu de maneira adequada a questões específicas das africanas, como, por exemplo, o que os direitos reprodutivos e sexuais significam realmente para estas mulheres ou como prevenir uma gravidez indesejada, ou ainda, como melhorar a vida das africanas, capacitando-as a tomarem decisões para melhorar seu status e, por fim, como convencer a comunidade a permitir que as mulheres tomem decisões com um envolvimento limitado desta mesma comunidade.

Rose Gawaya e Rosemary Mukasa argumentam que o Protocolo das Mulheres é "nativo, criado por africanos para africanos"19. Embora seja verdade que o documento foi elaborado por africanos (como se pode notar na composição da equipe que o redigiu), permanece o questionamento se o protocolo atende às aspirações de preservar os valores positivos da África, considerando os interesses de toda a sociedade. Apesar de bem intencionado, o documento continua com uma orientação ocidental - ele promove o individualismo ou a autonomia das mulheres. As "vozes africanas" no Artigo 14 são aquelas educadas no Ocidente, políticas e acadêmicas oriundas das elites da África. Como Jack Donnelly afirmou, são pessoas que reconhecem a relatividade dos conceitos, mas que estão presas à concepção ocidental de modernização e aldeia global20 .

(19) GAWAYA, Rose; SEMAFUMU MUKASA, Rosemary. The African Women's Protocol: A New Dimension for Women's Rights in Africa. Gender and Development, v. 13, n. 3, p. 42-50, 2005.

(20) DONNELLY, Jack. Human Rights and Human Dignity: An Analytic Critique of Non-western Conceptions of Human Rights. American Political Science Review, v. 76, n. 2, june, p. 303-316, 1982. Disponível em: <http://pt.scribd.com/doc/62712826/An-Analytic-Critique-of-Non-WesternConceptions-of-Human-Rights>. Acesso em: 23 fev. 2012. Também MUMBI, Machera. Opening a Can of Worms: A Debate on Female Sexuality in the Lecture Theatre. In: ARNFRED, S. (ed.). Rethinking sexualities in Africa.154, Lund: Nordic Africa Institute, 2004. 
O Protocolo das Mulheres não vocaliza o conhecimento local das africanas e, deste modo, falha ao não tratar de importantes relações entre a dinâmica cultural local e a ideologia de gêneros. É um instrumento contundente que, em sua adesão à promoção de padrões universais dos direitos reprodutivos e sexuais da mulher, pode facilmente ser percebido como uma ameaça às práticas e tradições culturais; portanto, como um documento neocolonialista.

O Artigo 14 concede à mulher o direito, como um indivíduo, à plena autonomia nas decisões relativas ao seu corpo, independentemente das leis ou padrões da comunidade na qual habita. A ideia de autonomia absoluta, baseada no indivíduo como uma prioridade relevante, não é consistente com a noção coletiva de sociedade, ao contrário, trata-se de um conceito que muitas africanas consideram estrangeiro; ele não tem como base a compreensão das experiências femininas embebidas em uma rede de relações, que é típica das sociedades e comunidades africanas. Por exemplo, o tema da reprodução envolve decisões que devem ser tomadas por homens e mulheres, não por mulheres sozinhas. Na sociedade africana, reivindicações de autonomia não são comuns ou mesmo conhecidas; a ideia de absoluta autonomia soa estrangeira e, por essa razão, é difícil atrair o apoio necessário para efetivar mudanças sociais. Qualquer posicionamento sobre reprodução deve considerar o equilíbrio entre os interesses das mulheres e da comunidade e não pode ignorar a realidade das africanas.

Defendendo o individualismo, o Artigo 14 assume que a cultura africana mudará para acomodar as preocupações individuais da mulher, considerando que os direitos humanos, como um conceito revolucionário, poderá alterar a face da sociedade. Isso pode ser difícil, se não impossível, de se alcançar, ainda mais porque a cultura, por si só, é um direito humano protegido ${ }^{21}$. Tanto como a cultura não é estatística e algumas mulheres estão lutando para efetivamente mudá-la, outras africanas em sociedades tradicionais (educadas ou não) valorizam suas tradições e querem protegê-las, um desejo arvorado na noção de que a cultura faz delas o que elas são ${ }^{22}$. Muitas africanas não querem perder suas identidades ${ }^{23}$. Mais, o Protocolo das Mulheres pode ter todas as melhores intenções, mas é a decisão feminina que está diretamente envolvida com o exercício do direito, a mulher é a "agente" com o qual se conta

(21) A Carta Africana dos Direitos Humanos foi adotada em 27 de junho de 1981 e entrou em vigor em 21 de outubro de 1986. Art. 17(2) e (3) afirmam que todo indivíduo "deve tomar parte da vida cultural da comunidade livremente" e que "a promoção e proteção dos valores morais tradicionais reconhecidos pela comunidade deve ser um dever do Estado". AFRICAN COMISSION ON HUMAN AND PEOPLE'S RIGHTS. African Charter on Human and Peoples' Rights (ACHPR), 1981. Disponível em: <http://achpr.org/english/_info/charter_en.html>. Acesso em: 23 fev. 2012.

(22) TAMALE, Sylvia. The Right to Culture and the Culture of Rights: A Critical Perspective on Women's Sexual Rights in Africa. Feminist Legal Studies, v. 16, p. 47-69, 2008.; TAMALE, Sylvia. Gender Trauma in Africa: Enhancing Women's Links to Resources. Journal of African Law, v. 48, n. 1, 2004. p. 50.

(23) HELLUM, Anne. Women's human rights and legal pluralism in Africa: mixed norms and identities in infertility management in Zimbabwe. Tano: Mond Books, 1999. 
para assegurar a implementação do documento ${ }^{24}$. Por exemplo, uma pesquisa em Gana mostrou que as mulheres não acham que serão capazes de continuarem férteis sem a aprovação de seus maridos ${ }^{25}$ e que elas não esperam ter autonomia reprodutiva, mas sim, esperam que as decisões a respeito desse assunto sejam tomadas pelos seus parceiros, os quais têm um poder relativo no exercício desse direito.

De acordo com a mesma pesquisa, na África Ocidental, a educação não é particularmente um fator de mais autonomia reprodutiva ${ }^{26}$. A autonomia feminina em Gana talvez não seja traduzida em autonomia reprodutiva precisamente porque a reprodução é controlada por linhagens e não por indivíduos ${ }^{27}$. O estudo concluiu ainda que, haja ou não diferenças em metas de reprodução, a desigualdade de gêneros ainda interfere em decisões sobre a natalidade. É fácil entender porque isso acontece, pois a intenção do parceiro com mais poder determina o comportamento do casal. Mas, a desigualdade de gêneros pode por si própria influenciar as intenções em relação à natalidade, criando a impressão de que não há conflito: as mulheres podem adequar seus objetivos para evitar disputas com o parceiro. Embora, homens também possam adaptar suas intenções, estudos mostram que os interesses dos maridos influenciam significativamente nos propósitos das mulheres, mas não o contrário ${ }^{28}$.

O Artigo 14 parte da premissa de que as sociedades africanas se modernizaram a tal ponto que a mulher se liberou dos interesses comunitários e do sistema de família patriarcal, que perpassa amplamente a maioria das comunidades na África. As instituições patriarcais, compreendidas no contexto africano, são sistemas de relações sociais e poderes, pelos quais os velhos dominam os jovens, os homens dominam as mulheres e os descendentes homens das famílias de mais poder dominam os outsiders que se casam ou são adotados pelo clã ${ }^{29}$. Em graus variados e em diferentes contextos, a família patriarcal e os sistemas comunitários impõem a vontade coletiva dos membros mais velhos e poderosos sobre as meninas ou mulheres, resultando em famílias nas quais elas têm pouco controle sobre trabalho, sexualidade, o intervalo entre as gestações e o número de filhos.

É, portanto, uma ilusão falar em uma África ideal onde a mulher realmente tem "liberdade" e autonomia em relação ao seu corpo. Uma pesquisa no Zimbábue revelou que as mulheres que não conseguem procriar questionam sua feminilidade

(24) BREMS, Eva. Protecting the Human Rights of Women. In: LYONS, Gene M.; MAYALL, James.(eds.). International human rights in the twenty-first century: protecting the rights of groups. Oxford:Rowman \& Littlefield Publishers Inc, 2003. p. 100-124.

(25) DEROSE, Laurie; DODOO, Nu-amoo; PATIL, Vrushali. Fertility Desires and Perceptions of Power in Reproductive Conflict in Ghana. Gender Society, v. 16, p. 53, 2002.

(26) Id. Ibid. p. 55

(27) Id. Ibid. p. 55. V. também YAW, Oheneba-Sakyiet al. Female autonomy, decision making and demographic behaviour among couples in Ghana. New York: Potsdam, 1995.

(28) DEROSE, Laurie; DODOO, Nu-amoo; PATIL, Vrushali. op. cit., p. 57.

(29) DIXON-MUELLER, Ruth. Population policy and women's rights, transforming reproductive choice. Westport; Praeger,1993. p. 15-19. 
e propósito de vida. Por quê? Porque elas são rejeitadas pela comunidade ${ }^{30}$. 0 mesmo estudo demonstrou que ter filhos era fundamental para os pais realizarem seus papéis culturalmente definidos de dominância masculina e de identidade feminina e para seu bem-estar emocional.

A maternidade oferece às mulheres o status de adultas, assim, elas devem lidar com as perspectivas da comunidade e terem filhos para se tornarem adultas ${ }^{31}$.

O Artigo 14 também simplifica a complexa relação de força entre homens e mulheres ${ }^{32}$. Como Carol Smart observou, a aquisição de direitos em uma determinada área pode criar a impressão de que as diferenças de força teriam sido "resolvidas" e que o exercício do poder tem pouco a ver com os direitos legais ${ }^{33}$. O que deve ser abordado é a realidade da situação das relações de poder entre mulheres e homens e as diferenças entre as mulheres. A habilidade de negociar sexo seguro ou controle da reprodução depende do peso da pessoa dentro do relacionamento. A capacidade de resistir ao sexo forçado, evitar a gravidez, satisfazer desejos e ter prazer sexual depende das relações de poder nos vínculos sociais ${ }^{34}$. Em um estudo ganês, conduzido por Adomako Ampofo, descobriu-se que, embora a mulher possa querer controlar seu desejo de ter filhos, ela pode não ser capaz, por causa das disparidades de força ${ }^{35}$. A pesquisa mostrou que, se um homem quer mais filhos, é melhor a mulher aceitar a vontade masculina do que correr o risco de seu marido se casar com outra esposa, para alcançar seus objetivos paternais.

O Artigo 14 não leva em consideração vários fatores - políticos, sociais e econômicos - relacionados à opressão contra as mulheres, e parte do princípio de que a aceitação dos direitos humanos é o suficiente para equilibrar a competição de forças entre homens e mulheres ${ }^{36}$. Por exemplo, a maioria das africanas não tem os meios financeiros para fazer valer suas decisões ${ }^{37}$. Um princípio de direito que expõe a integridade física, em uma sociedade na qual a realidade sempre coloca as mulheres sob a dependência econômica de seus parceiros do sexo masculino, é inútil. Ele promove formalmente a escolha individual, enquanto, na realidade, elas são dependentes financeiramente de seus parceiros.

(30) RUNGANGA, Agnes; SUNDBY, Johanne; AGGLETON, Peter. Culture, Identity and Reproductive Failure in Zimbabwe.Sexualities, v. 4, p. 315, 2001.

(31) RUNGANGA, Agnes; SUNDBY, Johanne; AGGLETON, Peter. op. cit.

(32) KEMP, Karoline.General situation of women in Africa. In: MUSA, Roselynn; MOHAMMED, Faiza; MANJI, Firoze. Breathing life into the African Union Protocol on Women's Rights in Africa. 3, [s. I.]: FAHAMU, 2006.

(33) SMART, Carol. Feminism and the power of law. London: Routledge, 1989. p. 145.

(34) MUKASA, Sarah. Domesticating the Protocol. In: MUSA, Roselynn; MOHAMMED, Faiza; MANJI, Firoze (eds.). Breathing life into the African Union protocol on Women's Rights in Africa 28 [s. I.]: FAHAMU, 2006.

(35) AMPOFO, Adomako. Gender inequalities, Power in Unions, and Reproductive Decision Makingin Ghana. PhD dissertation, Vanderbilt University, Nashville, TN. (unpublished).

(36) BEVERIDGE, Fiona; MULLALLY. Siobhan. International Human Rights and Body Politics. In: BRIDGEMAN, Jo.; MILLNS, Susan (eds.). Law and body politics: regulating the female body. v. 240. London: Dartmouth Publishing Co. Limited, 1995.

(37) TAMALE, Sylvia.The Right to Culture and the Culture of Rights: A Critical Perspective on Women's Sexual Rights in Africa. op. cit., p. 24, 50 e 61 
Por razões estratégicas, essa abordagem generalista pode ser apropriada em certos contextos, mas, em relação aos direitos reprodutivos e sexuais sua aplicabilidade é duvidosa. A aceitação das reivindicações dos direitos humanos é adequada em situações nas quais os direitos reclamados advogam que tanto homens, como mulheres são iguais perante a lei, ou que ambos os sexos devam receber salários iguais quando exercem as mesmas funções. Isso acontece quando a máquina do Estado, mandatória do cumprimento deste direito, pode ser responsabilizada. Porém, em se tratando de direitos reprodutivos e sexuais, pela natureza das relações envolvidas (usualmente relacionamentos íntimos) e do assunto em questão (o corpo feminino), a responsabilização e o monitoramento destes direitos não podem ser estabelecidos satisfatoriamente, sem levar em consideração a vontade própria e o interesse pessoal. O corpo da mulher envolve temas de profunda complexidade social, política, econômica, sexual e psicológica. Ele é um campo de luta, definição e controle e é extensivamente regulado e confinado por normas e práticas sociais. Portanto, qualquer regulação sobre ele é sensível e necessita de cuidadosa reflexão.

O Artigo se estende a todas as mulheres da África, independentemente de suas relevantes diferenças, que se manifestam entre ricas e pobres, urbanas e rurais, casadas ou solteiras, educadas ou não, e assume que todas as africanas são iguais. O Artigo pode ser incapaz de alcançar seus objetivos. Não há dúvidas de que a maioria das africanas vive em áreas rurais e tem baixo nível educacional e, por isso, tem falta de recursos e informação. Estas mulheres, ipso facto, não serão protegidas por este artigo. Essa situação é especialmente significante no que tange ao acesso a serviços médicos para o aborto legal, natalidade e planejamento familiar, que são desigualmente distribuídos, de acordo com as circunstâncias materiais.

O Artigo não faz referências a mulheres com deficiências físicas e mentais as quais contam com menos oportunidades. Elas são continuamente violentadas porque não podem se defender e algumas vezes são esterilizadas compulsoriamente a fim de livrar o país das "crianças de rua" ${ }^{38}$. Embora, o Art. 23 do Protocolo das Mulheres trate desse grupo de mulheres, ele apenas obriga os Estados signatários a tomarem medidas especiais para permitir o acesso delas ao mercado de trabalho, treinamento profissional e participação nas políticas decisórias. Ele também obriga os países a protegerem estas mulheres de qualquer forma de violência, incluindo o abuso sexual. Isso não é suficiente. Uma referência especial deveria ter sido feita para obrigar os Estados e as instituições não estatais a oferecer a estas mulheres todos os recursos possíveis para assegurar a proteção de seus direitos reprodutivos e sexuais. $\mathrm{O}$ Artigo 14 deveria ter ido milhas à frente $\mathrm{e}$ previsto que os Estados deveriam dar especial atenção e oferecer serviços para mulheres com deficiências em razão da dupla discriminação que elas enfrentam (como mulheres e como pessoas com deficiências).

(38) SSENYONJO, Manisuli. Culture and the human rights of Women in Africa: between light andshadow. Journal of African Law, v. 51, n. 1, p. 39 -67, 2007. 
O Artigo também é falho ao definir os termos "direitos reprodutivos e sexuais". Seu texto usa a frase "saúde reprodutiva e saúde sexual". Como apresentados na seção de conceituação, estes termos (saúde reprodutiva / direitos e saúde sexual / direitos) diferem no aspecto da saúde como um subconjunto dos direitos humanos. Se interpretada de maneira estrita, a frase "saúde reprodutiva e sexual" se refere a um aspecto da saúde e não compreende todos os princípios gerais dos direitos humanos. A saúde reprodutiva implica o direito a todos os serviços de reprodução e saúde, mas pode não necessariamente incluir o direito a tomar decisões em relação à reprodução sem discriminação. Isso porque a não discriminação não se aplica à categoria da saúde, mas é um princípio geral nos direitos humanos.

Apesar da utilização dos termos "direitos reprodutivos" e "direitos sexuais" ter se tornado comum nos textos e análises internacionais, há uma grande variação na extensão de sua assimilação, interpretação e significação, pelos países e pelas pessoas africanas ${ }^{39}$. Em algumas nações, a proteção dos direitos reprodutivos e sexuais deve ser aplicada apenas dentro do quadro do casamento; ou pode significar proteção dos direitos de reprodução e sexuais com propósito de procriação, deixando de lado as atividades não procriadoras; ou a contracepção pode ser interpretada como um recurso usado apenas por casais e com o consentimento dos cônjuges. Os países africanos podem se beneficiar dessas ambiguidades para ordenar suas legislações nacionais de acordo com suas interpretações, o que pode ser prejudicial às mulheres, uma vez que esta interpretação poderia possivelmente ignorar todas as outras mulheres com vida sexual ativa. Por essa razão, teria sido útil se os redatores do artigo oferecessem referências aos países, nas quais eles pudessem se apoiar.

Ademais, o Artigo 14 não trata da garantia dos direitos sexuais. Ele menciona a saúde sexual no item "Saúde e direitos reprodutivos", mas não articula claramente as escolhas sexuais: quando, onde, como e com quem uma pessoa pode manter relações sexuais e como tais escolhas podem ser protegidas. Essa omissão pode ser interpretada como um limitador a qualquer proteção ou análise sobre sexo sem fins de procriação, de tal forma que as mulheres, cujo comportamento sexual não se adeque ao círculo da reprodução, não estarão protegidas. Como preveniu Alice Miller, os direitos das mulheres e os direitos sexuais têm sido contidos pela sua dependência dos conceitos de saúde reprodutiva e risco sexual, o que tem chamado a atenção para a necessidade de proteger a mulher como um indivíduo, mais do que promover seus direitos ao exercício dos direitos ${ }^{40}$. Essa abordagem reduziu a sexualidade feminina a um corpo que sofre e que precisa ser protegido

(39) CORREA, Sonia. From Reproductive Health to Sexual Rights: Achievements and Future Challenges. Reproductive Rights Matters, 1997. Série 10.

(40) MILLER, Alice. Sexuality, violence against women, and human rights: women make demands and ladies get protection. Health and Human Rights: an International Journal, v. 7, n.2, p. 16-46, 2004. Disponível em: <http://www.hhrjournal.org/archives-pdf/4065347.pdf.bannered.pdf>. Acesso em: 20 fev. 2012. 
pela lei e pelo Estado. Falta pensar nos corpos das mulheres como necessitados da proteção concedida pela participação atuante e igualitária ${ }^{41}$.

Por fim, o problema central relacionado ao Artigo 14 é a falta de abrangência em estabelecer o equilíbrio adequado para a efetivação dos direitos reprodutivos e sexuais das mulheres, a partir da perspectiva das questões cruciais dos direitos humanos e da dignidade humana. Comunidades africanas estão lutando para estabelecer as suas próprias abordagens dentro da cultura mais ampla das relações e interações humanas, em especial no que diz respeito a esse individualismo que é preconizado na legislação internacional de direitos humanos $^{42}$. O ponto aqui é que o foco primário deve permanecer no principal e verdadeiro objetivo, centro da inquietação da humanidade com relação às muIheres: a promoção, mais abrangente possível, de uma vida digna para que elas sejam capazes de desfrutar destes direitos. O Artigo 14 realmente contribui para a realização desse objetivo ao criar um direito escrito para as mulheres. Porém, esta contribuição é ameaçada pelo perigo em tentar fazer com que as mulheres se beneficiem destes direitos como uma obrigação legal. Deve-se encarar a realidade de que, no contexto geral da promoção e proteção dos direitos das mulheres, o direito da mulher em controlar seu corpo continua sendo apenas uma possibilidade pouco efetiva, a menos que a comunidade o aceite totalmente.

Tendo considerado as limitações do artigo, criticaremos agora os subartigos individualmente.

\section{Artigo 14(1) - o direito ao controle da natalidade}

O Artigo 14(1) (a) garante à mulher o direito de controlar a natalidade, de decidir quando engravidar e quando parar de ter filhos, além do intervalo entre as gestações. Através da história, indivíduos e casais têm usado uma variedade de métodos de controle da natalidade, incluindo o prolongamento do celibato, períodos de abstinência, interrupção do coito, uso de ervas e dispositivos mecânicos ${ }^{43}$. A fertilidade feminina (ou a falta dela) é vista, na África tradicional, como um tema sobre o qual a sociedade tem imenso interesse, enraizado em seu discurso moral ${ }^{44}$. O direito ao controle da natalidade não é apenas uma questão relacionada aos direitos femininos ou liberdades, mas também um assunto da sociedade, levantando questionamentos sobre a legitimidade da comunidade em ditar comportamentos.

Para a sociedade africana, uma alta taxa de fertilidade (e um número considerável de crianças que sobrevivem) está associada à alegria e a uma vida boa e é sinal de boa educação. Isso não quer dizer que uma mulher não tenha

(41) Id. Ibid

(42) ODINKALU, Chidi Anselm. Back to the future: The imperative of prioritizing for the protection ofhuman rights in Africa. Journal of African Law, v. 47, n.1, p. 1-37, 1997.

(43) DIXON-MUELLER, op. cit.

(44) MCLEAN, Sheila.Women, Rights and Reproduction, In: MCLEAN, Sheila (ed.). Legal Issues inReproduction. Dartmouth: Dartmouth England, 1990. p. 213-228. 
poder de decisão sobre o assunto, inclusive sobre a quantidade de filhos que deseja. No entanto, mulheres com poucos ou sem filhos não são tão respeitadas e podem ser consideradas um passivo social. A esterilidade está associada ao mal e as mulheres estéreis são consideradas responsáveis por sua condição ou por terem herdado a esterilidade de seus ancestrais. A sociedade espera que as mulheres tenham filhos para assegurar a continuidade da humanidade e da linhagem do clã ${ }^{45}$. Na Nigéria, por exemplo, as decisões conjuntas sobre muitos aspectos da reprodução são poucas e o assunto é de dominância dos homens ${ }^{46}$.

A ideia de dar às mulheres o direito de controlar seus corpos e sua natalidade não é difícil de entender, uma vez que os direitos humanos asseguram a toda pessoa o direito à liberdade e à segurança pessoal. O que há de particular nessa ideia é que o livre exercício do poder da mulher cria um conflito em potencial com outras partes que podem não estar diretamente envolvidas, mas que são afetadas pelas decisões tomadas. Isso ocorre porque, se a mulher exercitar seu poder de decisão sem considerar as circunstâncias, o conflito decorrente dessa atitude irá afetar as relações de dependência entre a mulher e as outras partes envolvidas - seu parceiro e a sociedade. As mulheres devem, portanto, evitar qualquer conflito para uma boa coexistência com todos.

Identificamos três partes com interesses relacionados ao direito de controlar o próprio corpo, as quais serão detalhadas com o objetivo de balancear as diferentes reivindicações. Dentro de uma perspectiva dos direitos humanos, temos as mulheres que defendem estes direitos e seu livre exercício e que devem ser livres para viver uma vida digna, ter suas escolhas respeitadas, afirmar o direito à livre expressão e exercitar a autodeterminação ${ }^{47}$. Há também os homens que afirmam seus interesses como maridos e potenciais pais. As reivindicações masculinas estão baseadas em vários documentos, que determinam especificamente que os "pais" devem ser responsáveis por suas crianças. A terceira parte interessada, a comunidade na qual a mulher se insere, reivindica que "todos têm deveres para com a comunidade onde a liberdade e o completo desenvolvimento da personalidade é possível"48. Isso implica que a mulher, ao exercer o irrestrito direito sobre sua fertilidade, deve considerar as condições e circunstâncias da comunidade onde vive. Para a comunidade, em virtude de sua biologia, a mulher tem o dever de assegurar a continuidade da raça humana.

(45) HELLUM, op. cit., p. 141-144

(46) KUPONIYI, Francis; ALADE, O. A. Gender dynamics and reproduction decision making amongrural families in Orire Local Government Area of Oyo State, Nigeria. Journal Of Social Science, v. 15,n. 2, p. 101-104, 2007.

(47) INTERNATIONAL Covenant on Social and Civil Rigths(ICSCR). Organização das Nações Unidas, 1966. Art. $1^{\circ}$. Disponível em: <http://www2.ohchr.org/english/law/ccpr.htm>. Acesso em 20 fev. 2012; INTERNATIONAL Covenant on Economic, Social and Cultural Rights (ICESCR). Organização das Nações Unidas, 1966. Art 1 ${ }^{\circ}$. Disponível em: <http://www2.ohchr.org/english/law/ cescr.htm>. Acesso em: 20 fev. 2012.

(48) UNIVERSAL Declaration on Human Rights (UDHR). Organização das Nações Unidas, 1948. Art. 29. Disponível em: <http://www.un.org/en/documents/udhr/>. Acesso em: 20 fev. 2012. 
Essas diferentes reivindicações das partes envolvidas com o tema do controle sobre o próprio corpo não são balanceadas pelo Artigo, deixando para os Estados a tarefa de encontrar um meio termo. Entretanto, a legislação sozinha não consegue ter impacto sobre o exercício desses direitos, sem que haja outras condições favoráveis.

Outro questionamento que surge com esse subartigo é se o direito ao controle da natalidade presumivelmente envolve o direito ao tratamento da infertilidade por meio de tecnologias de reprodução assistida ${ }^{49}$. Há acadêmicos que defendem que $\operatorname{sim}^{50}$, uma vez que o direito moral de uma mulher fértil a ter filhos é o mesmo para uma mulher estéril. Mulheres que não sejam férteis também gostariam de se perpetuar e criar um filho biológico; sua infertilidade não deveria desqualificá-las para essa possibilidade de realizar seus direitos reprodutivos e sexuais.

A interpretação desse direito também resulta da interpretação dos princípios fundamentais de não discriminação e de dignidade humana, do direito humano de ter uma família e do direito de se beneficiar do progresso científi$\mathrm{co}^{51}$. Argumenta-se que os avanços da ciência criaram métodos que auxiliam a mulher a engravidar e que as mulheres teriam o direito a utilizar estes métodos e, sendo assim, o Estado deveria oferecê-los a todas que deles precisarem. A Conferência Internacional sobre População e Desenvolvimento (CIPD) estimula homens e mulheres a compartilhar das descobertas científicas. De acordo com a Organização Mundial da Saúde, o progresso científico oferece meios para remediar ou superar a infertilidade patológica ${ }^{52}$. O direito reconhece o direito dos homens de se beneficiarem deste progresso, chamando os governos a darem prioridade ao desenvolvimento de alternativas de controle da natalidade, como preservativos e vasectomia ${ }^{53}$. O direito ainda precisa ser efetivamente aplicado para que se exija dos governos essas medidas. A CIPD reconhece que esses benefícios são progressivos e que os Estados devem torná-los disponíveis por etapas. Em razão dessa provisão, as mulheres reclamam o direito positivo ao tratamento da infertilidade, o que implica que os governos têm o dever de atender a essa reivindicação e que o Estado deve providenciar um sistema de cuidados à saúde para o tratamento da infertilidade.

(49) Tecnologias de reprodução assistida é um termo geral que engloba vários métodos de fertilização que compartilham uma característica comum: a manipulação do óvulo e do esperma para tentar a fertilização. Disponível em: <http://www.cdc.gov/nccdphp/drh/ARTOO/PDF>. Acesso em: 1 out. 2006.

(50) DIXON-MUELLER, op. cit.

(51) UDHR, op. cit., Art. 27(2); ICCPR, op. cit., Art. 15; ACHPR, op. cit., Art. 22. Como avanços científicos e seus benefícios considerou-se outras áreas e não especificamente a de fertilização assistida.

(52) Disponível em: <http://www.who.int/reproductive-health/publications/rhr-00_1/RHR_00_1_ Chapter3part2.htm>. Acesso em: 14 nov. 2007.

(53) INTERNATIONAL Conference on Population and Development (ICPD), Cairo: Organização das Nações Unidas, 1994. §12.14. Disponível em: <http://web.unfpa.org/icpd/icpd-programme.cfm>. Acesso em: 20 fev. 2012. BEIJING Declaration and Platform for Action. United Nations Fourth World Conference on Women, Organização das Nações Unidas, 1995. Disponível em: <http://www.un.org/ womenwatch/daw/beijing/pdf/Beijing\%20full\%20report\%20E.pdf>. Acesso em: 20 fev. 2012. 
Por mais que concordemos com o avanço do direito ao tratamento da infertilidade, acreditamos que a tecnologia reprodutiva não é nem um direito possuído nem um privilégio a ser defendido. Mulheres têm o direito a não se reproduzirem e também a se reproduzirem. Em nossa opinião, não há base na legislação internacional ou africana sobre os direitos humanos para interpretar que o direito ao tratamento da infertilidade seja incluído nos direitos reprodutivos. Infertilidade não é uma doença ou uma deficiência para a qual o Estado é obrigado a fornecer serviços de saúde. Se o Estado puder oferecer os serviços, eles estarão disponíveis para as mulheres que poderão utilizá-los, enquanto aquelas que não têm acesso a eles terão que suportar o desprezo da sociedade e não exigi-los como um direito humano.

Apesar do uso das técnicas de reprodução assistida parecer benéfico às mulheres, há argumentos de que elas possam ameaçar a liberdade feminina ${ }^{54}$. Feministas ocidentais e algumas ativistas africanas afirmam que a utilização destas tecnologias reforçam a dominação patriarcal e a identificação das mulheres com a gravidez e provimento ${ }^{55}$. Lori $B$. Andrews, embora destaque que estas técnicas oferecem às mulheres maior controle sobre sua fertilidade e maiores chances de estabelecer estruturas familiares alternativas, como as famílias monoparentais ${ }^{56}$, afirma que, ao mesmo tempo, medicalizam o processo de concepção, gravidez e nascimento, diminuindo o controle da mulher sobre as funções reprodutivas ${ }^{57}$.

Essa preocupação, entretanto, não é um problema para as africanas, que querem ser identificadas como "mães" e se orgulham disso. De fato, na África, as mulheres vão ao limite para conseguir gerar uma criança e não é incomum ver uma africana consultando herboristas tradicionais para ajudá-las a engravidar. As necessidades sociais e culturais de gerar um filho, especialmente um herdeiro, são uma grande pressão sobre as mulheres estéreis. A necessidade de filhos que irão apoiar financeiramente seus pais na velhice é uma grande preocupação e usualmente as mulheres não terão escolha a não ser reproduzirem-se ${ }^{58}$. Assim, o conceito de "vontade própria" previsto no Artigo é mais retórico do que real.

Outro ponto que surge da aplicação dessas tecnologias é a questão de quem deve ter acesso a elas. $\mathrm{O}$ acesso deve ser limitado à idade, estado civil

(54) MCLEAN, op. cit., p. 102

(55) RAO, Radhika. Constitutional Misconceptions. Michigan Law Review, v. 93, p. 1473, 1995.

(56) ANDREWS, Lori B. How is Technology changing the Meaning of Motherhood for Western Women. In: WIDDOWS, Heather; IDIAKEZ, Itziar; CIRION, Aitziber. (eds.). Women's reproducitve rights. NewYork: Palgrave Macmillan, 2006. p. 124-129. A autora também destacou que as tecnologias dereprodução assistida envolvem uma série de riscos, como experimentos inapropriados com mulheres,com técnicas que ainda não foram comprovadas como satisfatórias; legislação deficiente com relaçãoa estas tecnologias, deixando a mulher à mercê dos médicos; comoditização da reprodução por meio do comércio já que uma criança pode ter mais do que cinco pais (doador do esperma, doadora do óvulo, mãe de aluguel e o casal que vai cuidar da criança). Assim, as leis precisam ser implementadas para esclarecer os direitos e deveres de cada participante no drama da reprodução.

(57) Id. Ibid.

(58) LARA, Knudsen. Reproductive rights in a global context, South Africa, Uganda, Peru, Denmark, United States, Vietnam, Jordan. [s. I.]: Vanderbilt University Press, 2006. 
ou orientação sexual? Por exemplo, uma mulher de 60 anos pode ter acesso à tecnologia para engravidar? E casais lésbicos? Quem tem esse direito? O que acontece quando o uso dessas técnicas envolver não apenas os pais biológicos, mas também o pai genético doador do esperma, a mãe genética doadora do óvulo ou a mulher que engravida da criança, a mãe substituta, mas não tem relação genética com ela? Todos esses indivíduos têm interesses que requerem que o Estado repense conceitos anteriormente tidos como certos, incluindo a noção de paternidade. Colocar um limite sobre quem pode usar essas tecnologias pode resultar em discriminação.

Considerando a ambiguidade do assunto, o controle da natalidade ou a liberdade pessoal para decidir sobre o próprio corpo são temas que devem se transformar gradualmente, porque a lei não pode regulá-los de maneira satisfatória. Isso não quer dizer que a legislação não deva promover e encorajar a discussão; alternativas devem ser colocadas para as mulheres serem capazes de fazer escolhas a respeito de seus corpos. Assim, a adoção do Artigo 14 não é o único caminho para as nações africanas liberarem as mulheres para controlar sua natalidade. Também é importante que as comunidades mudem sua visão sobre o assunto.

\section{Artigo 14(1) (b) - o direito a decidir quantos filhos ter e quando engravidar}

O Artigo 14 (1) (b) garante à mulher africana o direito de decidir sobre o número de filhos que deseja e o intervalo entre uma gravidez e outra. Este direito está assegurado sem recurso aos direitos dos outros, como, por exemplo, o direito do pai biológico em tomar decisões a respeito de seus filhos. A Proclamação da Conferência de Teerã dá aos "pais" o direito de decidir sobre o número de filhos e sobre quando engravidar ${ }^{59}$. Subsequentemente, os documentos originários das conferências de direitos humanos - particularmente o texto da CIPD e da Conferência de Beijing - caracterizam este direito como para "casais e indivíduos" ou "pais", e seu exercício deve levar em consideração "as necessidades de suas vidas e o futuro das crianças e suas responsabilidades diante da comunidade"60. A Convenção para a Eliminação de Todas as Formas de Discriminação contra as Mulheres (A Convenção das Mulheres), em seu Art. 16(1) obriga os Estados a garantir a homens e mulheres, na condição de igualdade, os "mesmo direitos para decidir livre e responsavelmente sobre o número de filhos e o momento da gravidez".

A interpretação dessa provisão é que homens e mulheres, com liberdade e igualdade, têm que definir o momento de ter filhos. Isso não significa que cada parte deva decidir de maneira independente, pelo contrário. Já o Artigo 14 (1)

(59) PROCLAMATION of Tehran Final Act of the International Conference on Human Rights. Teerã: Organização das Nações Unidas, 1968.

(60) ICPD, op. cit., §12; Beijing Conference, op. cit., §95; NAIROBI Forward Looking Strategies for the Advancement of Women, Nairóbi: Organização das Nações Unidas, 1985. 
(b) dá plena autonomia à mulher, não importando os interesses masculinos, assumindo que ela é capaz de agir com independência. O Artigo diverge dos primeiros direitos humanos que responsabilizam homens e mulheres. O programa de ação do CIPD reconhece que ambos os sexos são parceiros iguais na vida pública e na privada e têm responsabilidades conjuntas sobre o assunto ${ }^{61}$.

Apesar das mulheres terem uma maior participação nos assuntos relacionados à reprodução, é importante considerar os interesses masculinos, a fim de equalizar a decisão a ser tomada. Imaginemos um cenário no qual uma mulher quer ter oito filhos e exige auxílio financeiro do homem e, se ele se recusa a tê-los, ela o processa judicialmente para o sustento das crianças. Esta mulher pode reclamar este direito para ter filhos? E, como o homem tem o dever de cuidar dos filhos, ele deve pagar? O homem pode alegar que ele foi coagido a ser pai e que não tem o dever de sustentar as crianças?

Outro ponto que chama a atenção é sobre quais interesses devem ser precedentes em caso de conflitos entre a mulher e o homem ou entre a mulher e a comunidade. $O$ que acontece se o homem quiser que a mulher tenha filhos e ela não quiser? E, se for o caso de a mulher querer e o homem não? As respostas a esses questionamentos dependerão das circunstâncias do caso; se o conflito é entre o homem e a comunidade, os interesses masculinos prevalecerão, porque o homem tem um interesse direto e imediato no gozo do direito, qual seja, ser responsável pelo bem-estar da criança.

No caso do conflito entre a mulher e a comunidade, o interesse feminino deveria prevalecer. No entanto, para qualquer decisão, ela deverá considerar as circunstâncias. $\mathrm{O}$ argumento tem como base o dever criado pela Carta Africana dos Direitos Humanos. Segundo os artigos 2 a 18 deste documento e o Art. 2 do Protocolo das Mulheres, os países são obrigados a eliminar a discriminação contra as mulheres e a assegurar que elas sejam capazes de gozar de seus direitos como estipulado nas declarações e convenções internacionais. Ao mesmo tempo, a Carta, em seu preâmbulo, enfatiza a preservação da família e da cultura e, em seu Art. 29(7), obriga cada indivíduo a "preservar e reforçar os valores culturais africanos em suas relações com outros membros da sociedade, no espírito de tolerância e diálogo e, em geral, contribuir para a promoção do bem-estar moral da sociedade".

Quais são os valores africanos "positivos" para serem protegidos? Quem determina o que é positivo - a comunidade ou o indivíduo? Estas perguntas são relevantes e não têm respostas precisas. Contudo, um valor positivo na sociedade africana é a ênfase no dever dos indivíduos para com a sociedade e para com os outros indivíduos. Este dever é muito importante para a preservação da paz e para a promoção do bem-estar social. Ele contribui para a construção e manutenção

(61) ICPD, op. cit., §4.24. Também prevê que é essencial melhorar a comunicação entre homens e mulheres em assuntos relacionados à saúde sexual e reprodutiva e a compreensão das responsabilidades conjuntas. 
do bem-estar do indivíduo assim como da sociedade. Uma vez que uma pessoa saiba que tem um dever para com os outros, ela vai se esforçar para cumprir com este dever. Este valor positivo tem um importante papel na satisfação das necessidades básicas do ser humano e na defesa da dignidade das pessoas.

As africanas sentem que têm um dever para com a comunidade. Okinna Okere afirma que "a concepção africana de homem não é a de um indivíduo isolado e abstrato, mas sim, a de um membro de um grupo imbuído de um espírito de solidariedade"62. As necessidades individuais de uma mulher, seus direitos, prazeres e sofrimentos são a trama de um tapete social que nega a individualidade singular mesmo em assuntos relacionados ao seu corpo ${ }^{63}$. Outro valor positivo que a Carta Africana dos Direitos Humanos estima é a família, considerada a "unidade básica natural da sociedade" 64 , que inclui a família estendida e é vista como um lugar onde a moral e a disciplina são transmitidas às crianças. Essa função é importante e é um meio de assegurar paz e harmonia na comunidade.

Se o conflito é entre o homem e a mulher, a melhor opção para ambos é uma solução que penda mais aos interesses femininos. Trabalhar em parceria com o homem não é uma traição à causa feminina; é inevitável, uma vez que as mulheres devem trabalhar junto com os homens na construção de parcerias pessoais, importantes para o desenvolvimento de seu próprio bem-estar moral, econômico e social. Estas parcerias deveriam ser construídas a partir de uma estratégia que assegurasse às mulheres não perderem de vista o objetivo de exercitar seus direitos reprodutivos e sexuais.

Embora a contribuição masculina para o nascimento de uma criança seja pequena (são as mulheres que engravidam e dão à luz), no longo prazo, essa diferença é apenas relativa, pois, ambos os sexos têm responsabilidade na proteção e educação dos filhos, como afirma o Art. 6(i) do Protocolo das Mulheres. O Art. 13(1) deste mesmo documento diz que "ambos os pais têm a responsabilidade primordial pela educação e desenvolvimento dos filhos".

Depois, a sociedade patriarcal da África espera que o homem (ou pai) seja financeiramente responsável pelos seus filhos. De fato, esta responsabilidade pode ser obrigada judicialmente ${ }^{65}$. O subartigo deveria considerar como atribuições de ambos os pais, e não apenas das mulheres, as questões referentes ao número de filhos que se deseja ter e ao intervalo entre as gestações.

(62) OKERE, Okinna Bertna. The Protection of Human Rights in Africa and the African Charter on Human and Peoples Rights: A Comparative analysis with the European and American systems. Human Rights Quarterly, v. 6, p. 141-148, 1984. Ver também MBAYE, Keba que afirma que "as leis e deveres têm dois lados da mesma realidade, duas realidades inseparáveis” In: MBAYE, Keb. International Commission of Jurists, Human and Peoples Rights in Africa and the African Charter. Geneva: International Commission of Jurists, 1986. p. 27.

(63) V. MBITI, John S. African religions and philosophy. 141, New York: Praeger, 1970.

(64) ACHPR, op cit., Art. 18

(65) No caso Re AylaMayanja Miscellaneous Application n. 2, 2005. A corte de Uganda entendeu que o pai de uma criança, legítimo ou não, tem o dever de sustentá-la. 
Como povos, os africanos enfatizam o grupo, a identidade e a comunidade ${ }^{66}$. Eles acreditam na sobrevivência de toda a comunidade e da família e têm um grande senso de responsabilidade coletiva, cooperação e interdependência. Assim, a natalidade é um tema para toda a família e não somente da mulher como indivíduo, como acontece nas sociedades ocidentais. Não se trata de um "negócio puramente de mulheres".

\section{Artigo 14 (1) (c) - o direito ao uso de contraceptivos}

O Artigo 14(1) (c) prevê que a mulher tenha o direito a escolher qualquer método contraceptivo, crucial para conciliar a vida sexual com os objetivos de ter filhos. Na África, somente $27 \%$ das mulheres utilizam contraceptivos ${ }^{67}$. Este percentual baixo é atribuído à falta e distribuição desigual de serviços, a limitações tecnológicas e à falta de conhecimento ${ }^{68}$. De acordo com a Organização Mundial da Saúde, o direito de acesso a métodos contraceptivos e informação e educação sobre planejamento familiar deve incluir três componentes: 1) acesso físico, isto é, contraceptivos devem estar disponíveis para as mulheres que desejam utilizá-los; 2) informação, de modo que as mulheres conheçam as vantagens e os efeitos colaterais do método contraceptivo e; 3 ) os programas de planejamento familiar devem ter como uma de suas metas assegurar a independência feminina na tomada de decisão sobre a reprodução ${ }^{69}$.

O direito ao uso de contraceptivos é um assunto com aspectos positivos e negativos para as africanas. Enquanto liberta a mulher do medo de uma gravidez não planejada, ele a expõe a potenciais riscos de saúde e deixa nas mãos de médicos o controle efetivo da decisão sobre como e quando usar contraceptivos, porque não há uma definição com relação à quantidade de informação que uma mulher precisa para fazer sua escolha, e porque o médico pode reter a informação que ajudaria a mulher a escolher. A aplicação desse direito está constantemente ameaçada pelos valores paternalistas e patriarcais, de maneira que, para a mulher ter acesso à contracepção, ela continua a depender mais da vontade do médico do que da garantia de um direito ${ }^{70}$.

Em muitas sociedades africanas, a organização social desencoraja a adoção de métodos contraceptivos e defende altas taxas de natalidade ${ }^{71}$. O uso

(66) COBBAH, Josiah A. M. African Valuesand the Human Rights Debate: an African Perspective. Human Rights Quarterly, v.9, n.3. p. 309-331, 1987.

(67) Disponível em: <http://www.un.org/esa/population/publications/contraceptive2003/WallChart_ CP2003_pressrelease.htm>. Acesso em: 26 out. 2007.

(68) Disponível em: <http://www.who.int/reproducitve-health/family-planning/index.html>. Acesso em: 26 out. 2007.

(69) WORLD HEALTH ORGANIZATION. Maternal Mortality Rate: Tabulation of Available Information. $2^{\text {nd }}$ Edition, Geneva: WHO, 1986.

(70) DOUGLAS, Gillian. Law, fertility and reproduction. London: Sweet and Maxwell, 1991. p. 41.

(71) WORLD HEALTH ORGANIZATION Report. Disponível em: <www.who.org> 
de contraceptivo varia em níveis nacional, regional, comunitário e individual ${ }^{72}$. No plano nacional, quando disponível, somente mulheres casadas, com o consentimento escrito de seus maridos, podem ter acesso a contraceptivos. Muitas mulheres ativas sexualmente e solteiras não procuram serviços de contracepção com medo de ficarem estigmatizadas socialmente ou por temerem o julgamento dos profissionais que atuam nestes serviços. Há também problemas associados com a falta de privacidade, alto custo e situação econômica ${ }^{73}$. Por exemplo, um estudo no Quênia mostrou que a aprovação masculina para o planejamento familiar é mais importante do que a feminina; a perspectiva do homem tem uma importância muito grande no uso ou não de contracepção ${ }^{74}$. Ainda no nível nacional, as políticas contraceptivas são fracas porque os políticos e burocratas acreditam que ainda há pouca demanda para elas ${ }^{75}$.

No plano comunitário, o casal sofre pressão de outros personagens relevantes como o clã e seus pais ${ }^{76}$, os quais assumem um interesse sobre assuntos ligados à fertilidade do casal. A comunidade pode se opor ao uso de contraceptivos, vistos como um caminho ocidentalizado para destruir a África. Com relação ao nível individual, antes de usar um contraceptivo, a pessoa deve decidir se quer ter filhos e quando, e qual método que pretende usar. Ainda nesse plano, a relação de força entre homens e mulheres e as normas culturais sobre a posição feminina na África ditam a natureza e a maneira de usar o contraceptivo. Estudos demonstram que programas de contracepção não têm sucesso na África porque não consideram a relação de forças entre os parceiros ${ }^{77}$, relação que está ligada à comunicação efetiva entre o casal. Mas, como a maioria das mulheres africanas vive em áreas rurais e não tem um nível de educação alto, o homem, o líder da casa, quase não é desafiado em suas decisões. O direito da mulher de decidir qual contraceptivo usar não dará frutos a menos que sejam mudadas para melhor as relações de poder e que não haja mais medo dos sogros e da comunidade. Em um estudo na Gâmbia, descobriu-se que as mulheres utilizam contraceptivos para controlar o intervalo entre as gestações e não para controle da fertilidade; mesmo assim, uma mulher irá parar de usá-los imediatamente, se temer que o seu parceiro ache que ela está tentando restringir o número de filhos ${ }^{78}$.

Como visto, o uso de contraceptivos não é uma prerrogativa apenas das mulheres e a mulher africana pode cometer erros ao decidir sobre esse assunto.

(72) FACTORS affecting contraceptive use in Sub-Saharan Africa. Disponível em: <http://www.nap. edu/catalog.php?record_id=2209>

(73) Id. Ibid.

(74) KIMUNA, Sitawa; ADAMCHAK, Donald. Gender relations: Husband-Wife Fertility and Family Planning Decisions in Kenya. Journal Of Biosociology Science, v. 33, p. 13-23, 2001.

(75) Id. Ibid.

(76) Disponível em: <http://en.wikipedia.org/wiki/Christian_views_on_contraceptive\#Current-view>. Acesso em: 14 nov. 2007.

(77) YAW, Oheneba-Sakyi; TAKYI, Baffour. Effects of Couples Characteristics on Contraceptive usein Sub-Saharan Africa: The Ghanaian example. Journal of Biosociology Science, v. 29, p. 33-49, 1997.

(78) BLEDSOE, Caroline. Constructing Natural Fertility: The Use of Western Contraceptive Technologies in Rural Gambia. Population Development Review, n. 20, p. 81-113, 2000. 
Com toda a oposição e as diferentes visões, as nações africanas e suas muIheres vão enfrentar dificuldades, pois terão que equilibrar todos os pontos de vista para a harmonia da comunidade.

\section{Artigo 14(1)(d) e (e) - o direito de ser informada sobre o parceiro}

O Artigo 14(1)(d) e (e) do Protocolo das Mulheres garante a elas o direito de serem informadas sobre sua saúde e sobre a saúde de seu parceiro, principalmente se infectados por doenças sexualmente transmissíveis, incluindo o vírus HIV. Antes da adoção do documento, os países africanos vinham implementando mecanismos para a redução das taxas de infecção. Em 1994, com a Declaração da Tunísia sobre a AIDS e a Criança na África ${ }^{79}$, em 1996, com a Declaração de Abuja sobre HIV/AIDS, Tuberculose e outras Doenças Infecciosas ${ }^{80} \mathrm{e}$, mais recentemente, em 2004, com Declaração de Igualdade de Gênero ${ }^{81}$, as nações africanas concordaram em promover a igualdade de gênero e o empoderamento das mulheres em todos os níveis.

A Plataforma de Ação de Beijing reconhece que a subordinação social da mulher e a relação de forças desigual em favor dos homens são determinantes na vulnerabilidade feminina ao vírus da AIDS ${ }^{82}$. A Organização Mundial da Saúde também destacou que:

HIV/AIDS e outras doenças sexualmente transmissíveis, uma transmissão que, algumas vezes, é consequência de violência sexual, têm efeitos devastadores sobre a saúde da mulher... Elas normalmente não têm poder para insistir na prática do sexo seguro e responsável e têm pouco acesso à informação e aos serviços de prevenção e tratamento ${ }^{83}$.

As consequências do HIV/AIDS vão além da saúde feminina, invadindo a maternidade, seu papel de cuidadora e sua capacidade de contribuir financeiramente com a família. Além disso, a falta de acesso a serviços de saúde de reprodução faz com que as doenças sexualmente transmissíveis não sejam detectadas, deixando as mulheres ainda mais suscetíveis ao HIV. A prevenção da AIDS e de outras doenças sexualmente transmissíveis é central na garantia dos direitos das mulheres.

(79) Adotada pela Organização da Unidade Africana (sigla eminglês, OAU), durante a Assembleia dos Chefes de Estado e de Governo, em Tunis, Tunísia, 1994, a Resolução sobre Relatórios Regulares de Status na OAU sobre a Implementação das Declarações sobre HIV/AIDS na África. $30^{a}$ Sessão Ordinária, 13 a 15 de junho, 1994. Disponível em: < http://www.africa-union.org/Official_documents/ Heads\%20of\%20State\%20Summits/hog/4HoGAssembly1994.pdf>. Acesso em: 20 fev. 2012.

(80) Adotada na 32a. Sessão Ordinária da Assembleia dos Chefes de Estado e de Governo da OAU, 1996. Disponível em: <http://www.un.org/ga/aids/pdf/abuja_declaration.pdf> . Acesso em: 20 fev. 2012. (81) Adotada em Maputo pela Assembleia dos Chefes de Estado e de Governo da OAU, 10 a 12 de julho, 2003. Disponível em:<http://www.africangenderaward.org/PDF_publications/ AfricaSolemnDec04.pdf>. Acesso em: 20 fev. 2012.

(82) A Conferência de Beijing, op. cit., §98, reconhece que as mulheres são mais vulneráveis física e biologicamente ao vírus HIV do que os homens, especialmente em países em desenvolvimento.

(83) WORLD HEALTH ORGANIZATION. Sexual and Reproductive Health Research Priorities for WHO for the period 1998-2003, 1997. p. 4-5. 
Esse subartigo tem dois componentes: o primeiro garante à mulher o direito à informação sobre sua saúde. A relação médico/paciente obriga o profissional a informar à paciente qual sua doença e qual tratamento será feito. O segundo componente garante e autoriza a mulher a conhecer a situação da saúde de seu parceiro, especialmente se ele estiver infectado com o HIV. A dificuldade deste subartigo está neste segundo item. O problema prático é: uma mulher pode perguntar ao seu marido ou parceiro se ele é soropositivo? O Artigo afirma que a mulher, como um indivíduo, deve ser informada a fim de que ela decida conscientemente sobre continuar o relacionamento ou sobre ter ou não relações sexuais (com ou sem proteção).

O subartigo não enfrenta a questão de que a maioria das mulheres africanas não tem poder para fazer tais questionamentos ${ }^{84}$. Muitas vezes, quando uma mulher pergunta ao seu parceiro se ele é soropositivo ou se pede a ele para usar preservativos, ela sofre violência doméstica ${ }^{85}$. Em outros casos, ela é financeiramente dependente do parceiro e não pode abandoná-lo; então, tem de conviver com ele, independentemente de suas condições de saúde. Além disso, algumas mulheres respondem às expectativas sociais, pelas quais, uma mulher deve cuidar de seu parceiro caso ele seja HIV positivo, e pode ser banida se assim não o fizer.

O compartilhamento de informação garantido pelo subartigo deve ser feito de acordo com as práticas e normas internacionais. Segundo o parágrafo 15(a) do Sumário das Diretrizes Internacionais sobre HIV/AIDS e Direitos Humanos, a proteção dos direitos humanos é essencial para uma resposta positiva à AIDS, uma "resposta efetiva requer a implementação de todos os direitos humanos, civis e políticos, econômicos, sociais, culturais e liberdades fundamentais, de acordo com os atuais padrões internacionais de direitos humanos"86. Em seguida, o documento [5(c)] afirma que:

Leis gerais sobre confidencialidade e privacidade devem ser promulgadas. Informações pessoais relativas ao HIV devem ser incluídas na definição de dados pessoais da relação médico/paciente para proteção e devem ser proibidos a divulgação ou o uso sem autorização de informações pessoais relacionadas ao HIV ${ }^{87}$.

Considerando essas diretrizes, como o direito garantido pelo subartigo pode se reconciliar com a garantia ao direito à privacidade que ambos os parceiros têm e que é protegido por instrumentos internacionais de direitos humanos? Como fica o tema da confidencialidade de dados médicos e da relação médico/paciente? Temos aqui um conflito entre dois instrumentos internacionais que é problemático, pois ameaça a coerência e a efetividade

(84) BANDA, Fareda. Blazing a Trail: The African Protocol on Women's Rights Comes into Force. Journal Of African Law, v. 50, n. 1, p. 72-84, 2006. Isso, no entanto, não significa que a mulher não tenha poder para decidir.

(85) Ver <http://cpp.org.za/>

(86) THE INTERNATIONAL Guidelines on HIV/AIDS and Human Rights. Disponível em: <http://data. unaids.org/Publications/IRC-pub07/jc1252-internguidelines_en.pdf >. Acesso em: 20 fev. 2012.

(87) THE INTERNATIONAL Guidelines on HIV/AIDS and Human Rights. op. cit. 
da lei. Pode-se argumentar, é claro, que diretrizes não são um "instrumento internacional" no sentido estrito da palavra, porque elas não são vinculantes, são apenas referências para os países. Esta argumentação, no entanto, não é muito útil. Pelo fato de que as diretrizes são resultados de esforços das Nações Unidas, elas são igualmente vinculantes para todos os Estados-membros da ONU. Para resolver esse possível conflito, as nações africanas têm que legislar considerando todas as possibilidades de tensão e buscar um equilíbrio, o qual, deve assegurar a confidencialidade e a privacidade das partes envolvidas.

A Diretriz 4 prevê que a legislação criminal não deve considerar como delitos específicos a transmissão deliberada e intencional do HIV; ela deve aplicar infrações gerais para esses casos excepcionais ${ }^{88}$. Ao determinar que é um direito feminino saber se o parceiro é soropositivo ou não, se o parceiro esconde essa condição, a violação da sua privacidade será um delito penal para o qual o Estado é obrigado a definir uma punição. A fim de se adequar à Diretriz 4, os países africanos deveriam obrigar todos a fazerem o teste de detecção do vírus da AIDS? Como os países irão provar que uma pessoa sabia de sua condição de soropositiva antes de ter relações sexuais com sua parceira? Será que isso não agravaria o problema, conduzindo as pessoas à clandestinidade e a evitarem o teste? As nações africanas estão diante de um dilema, especialmente porque a maioria das pessoas infectadas pelo HIV está na África e não sabe que é soropositiva.

Somando-se à questão da privacidade e da criminalização, o subartigo também cria um outro dilema em relação à informação, pois obriga o Estado a informar a mulher sobre a condição de saúde de seu parceiro. O subartigo entende que o Estado conhece todos os parceiros das mulheres de modo a ser capaz de disponibilizar a informação para elas. Como o Estado pode conhecer e mesmo monitorar os parceiros? Como o Estado pode conhecer o parceiro em casamentos polígamos e relacionamentos que não são registrados oficialmente? Mesmo que todos os casamentos sejam documentados, seria demais pedir ao Estado que monitore os parceiros. Além do mais, muitos casais simplesmente moram juntos. O Estado vai impingir o direito a estes casais? Como irá rastreá-los? Considerando-se os parcos recursos que muitos países africanos têm, seria criar um retrocesso na implementação desse direito, pois, os governos poderiam alegar que faltam recursos para monitorar os parceiros.

O subartigo não impõe obrigações expressas aos atores não estatais. Por que o dever de informar não foi colocado para o parceiro ou esposo ou doutores e hospitais, ao invés de ao Estado? Essa omissão de não comprometer atores não estatais significa que eles não podem ser responsabilizados. Com isso, as obrigações do Estado não podem ser adequadamente realizadas, pois, existem muitos outros deveres estatais mais importantes do que controlar relações.

(88) Id. Ibid. 


\section{Artigo 14(2)(c) - o direito ao aborto médico em circunstâncias excepcionais}

Esse subartigo obriga os Estados a proteger os direitos reprodutivos das mulheres, autorizando o aborto médico em casos de violência sexual, estupro, incesto e quando a continuação da gravidez coloca em risco mental e físico a saúde da mulher ou sua vida ou a do feto. Em outras palavras, implica que o Estado não deve permitir que toda grávida se submeta a um procedimento médico seguro a não ser sob determinadas circunstâncias (exceções ao aborto), sem nenhuma ligação com suas prioridades e aspirações. Ao colocar exceções ao direito ao aborto, definindo quando e como ela pode fazê-lo, este subartigo viola o direito à segurança da pessoa estipulado no Art. 4(1) do Protocolo das Mulheres ${ }^{89}$, pois força uma mulher que não quer continuar com a gravidez $\mathrm{e}$ que não se enquadra nas exceções a optar por tratamentos inadequados para interromper a gestação ${ }^{90}$. Em outras palavras, trata-se de discriminação. De acordo com a Convenção das Mulheres, "discriminação contra mulheres" inclui leis que "tenham o efeito ou o propósito de impedir a mulher de gozar de quaisquer outros direitos humanos ou liberdades fundamentais baseadas na igualdade"1. Ao criar exceções a este direito, o subartigo não apenas viola alguns direitos femininos, como também é discriminatório.

Não permitir que as mulheres decidam se a gravidez foi resultado de estupro, incesto ou violência sexual é uma ameaça tanto física como emocional. A mulher deve aguardar uma decisão judicial que vai definir se sua gestação é decorrente de um crime, porque as exceções, para a realização do aborto médico, são delitos penais que, primeiro, têm que ser provadas. Por outro lado, mesmo que se admita que não há nenhuma exigência de julgamento, antes da mulher poder fazer um aborto legal, existem atrasos decorrentes da espera da decisão sobre se a mulher se enquadra nas exceções. Essa é uma dificuldade para as mulheres.

Outro ponto diz respeito a quem determina que a gravidez representa um perigo à saúde da mulher, o que também é um empecilho ao exercício do direito ao aborto. Em muitos países, essa é uma atribuição de um comitê de especialistas

(89) Art. 4(1): "Toda mulher tem direito ao respeito a sua vida e à integridade e segurança de sua pessoa. Todas as formas de exploração, punição ou tratamento cruéis, inumanos ou degradantes devem ser proibidos".

(90) Não há dúvida de que, apesar da criminalização do aborto, muitas mulheres já se submeteram a abortos ilegais. As estatísticas mostram que $13 \%$ das mulheres africanas morrem em decorrência de complicações de abortos ilegais. Disponível em: <http://www.afro.who.int/press/2003/ regionalcommittee/pr20030904.html>. Acesso em: 26 out. 2007.

(91) A Convenção das Mulheres foi adotada em 18 de dezembro de 1979 e entrou em vigor em 3 de setembro de 1981. Define a discriminação contra as mulheres "considerando a igualdade entre homens e mulheres, como qualquer distinção, exclusão ou restrição feitas com base no sexo, que tenham o efeito ou o propósito de prejudicar ou anular o exercício dos direitos humanos e das liberdades fundamentais políticas, econômicas, sociais, culturais, civis ou de qualquer outro campo, pela mulher, independentemente de seu estado civil." 
que deliberam sobre o caso e fazem uma recomendação ${ }^{92}$, o que leva a atrasos com consequências físicas, emocionais e psicológicas. Mesmo considerando que os comitês sejam permanentes, não há garantia de que eles apliquem os mesmos padrões para todos os casos. A única forma de resolver esse contratempo seria deixar que a mulher decida de acordo com suas circunstâncias.

O gozo desse direito enfrenta muitas resistências de líderes religiosos. Muitos dos argumentos para limitar o aborto estão baseados na proteção dos direitos da criança não nascida ou do feto. A Igreja Católica Romana, em particular, defende que o direito ao aborto, garantido no Protocolo das Mulheres, é um objetivo malévolo e um ataque aos mais indefesos membros da sociedade - as crianças não nascidas. O direito reivindicado vai ao encontro das aspirações positivas da vida, representadas na herança cristã e nas tradições africanas.

Por outro lado, ativistas feministas argumentam que as mulheres deveriam ter direito ao aborto porque o corpo da mulher não é do Estado, nem dos médicos, nem do marido, parceiro ou pai da criança, não é dos líderes religiosos ou da comunidade e, mais importante, não é do feto ${ }^{93}$. Elas afirmam que o controle do aborto previsto no subartigo equivale a dizer que as grávidas devem sacrificar sua liberdade e aceitar os limites a sua autonomia e integridade física para proteger o feto; que limitar o aborto médico e deixar ao Estado a responsabilidade de legislar pelo feto é um passo perigoso em direção à negação total da autonomia da mulher gestante e à entrega do controle sobre o corpo da mulher ao Estado. Dessa maneira, sendo a grávida competente, a responsabilidade de decidir sobre o que acontece com o seu corpo deveria ser unicamente dela, com a qualificação de que a decisão deve ser tomada considerando as circunstâncias.

Os argumentos apresentados (da igreja e das ativistas feministas) estão muito distantes uns dos outros e não têm nenhum ponto em comum; ainda é preciso chegar a um equilíbrio para que esse direito seja realizado. Não se podem dobrar crenças religiosas e os Estados não convencerão os líderes religiosos a se curvar em direção aos avanços dos direitos femininos. A maioria dos países africanos, por outro lado, não pode legislar sobre nenhuma posição veementemente oposta aos preceitos religiosos. As nações africanas, sejam quais forem suas inclinações, valorizam a religião e não iriam contra seus ensinamentos. Se os Estados legislarem como prevê o subartigo, os líderes religiosos irão protestar; se não, quem protestará serão as feministas, que acusarão o Estado de não estar cumprindo com suas obrigações. Isso leva a África a um dilema.

(92) Em Uganda, três médicos qualificados determinam os riscos, segundo o Código Penal.

(93) OVERALL, Christine. Human reproduciton: principles, practices and policies. Toronto: Oxford University Press, 1993. p. 37. 


\section{CONSIDERAÇÕES FINAIS}

Este trabalho abordou questões relacionadas ao Artigo 14 do Protocolo das Mulheres, destacando os desafios para sua implementação. Especificamente, explicitou-se que a abordagem individualista do Artigo não será facilmente aceita na sociedade africana.

O texto analisado é um instrumento bem-vindo que trata de assuntos relativos às mulheres, os quais por um longo tempo não fizeram parte das agendas regionais e internacional. Ele garante os direitos reprodutivos e sexuais femininos, porém, em uma linguagem ambígua e vaga, o que tornará sua implementação embaraçosa.

O Artigo 14 é baseado na hipótese de que a mulher na África é um indivíduo à parte da comunidade e que pode decidir sobre seu corpo independentemente dos interesses da sociedade. Trata-se de um artigo bastante ambicioso que não mostra uma perspectiva africana dos direitos das mulheres. Uma mulher não é uma entidade totalmente independente, desconectada da sociedade na qual vive. Tampouco ela é um simples componente em uma máquina impessoal na qual seus valores, objetivos e aspirações estão subordinados aos da coletividade. Ela é um pouco das duas coisas e, se seus interesses forem genuinamente respeitados, ela deveria ter a chance de decidir, considerando suas responsabilidades e deveres com relação à comunidade.

Enquanto defensores da ratificação e internalização do Protocolo das MuIheres pelos países africanos, os ativistas devem compreender que as mulheres da África se reconhecem apenas por meio de suas conexões com os outros e que as comunidades existem somente pelo relacionamento sinérgico com suas mulheres. Para efetivar as mudanças nas comunidades, de modo a permitir que as mulheres exerçam livremente seus direitos reprodutivos e sexuais, as africanas devem promover essas relações dinâmicas e transformadoras, encorajando o diálogo entre as mulheres e a sociedade. Os direitos reprodutivos e sexuais devem ser introduzidos nas comunidades como uma esperança para que as vozes silenciosas das africanas possam ser ouvidas. Assim, as comunidades vão se desenvolver melhor.

Esses direitos devem ser abordados de maneira a permitir que os legisladores tenham como foco não apenas a mudança de leis discriminatórias, como também a elaboração de políticas públicas que atendam às necessidades sociais, econômicas, culturais e educacionais das mulheres. Isso somente poderá ser feito com a clara compreensão sobre o que significam direitos reprodutivos e sexuais para a mulher na África e sobre quais são as visões da comunidade na qual a mulher vive. 


\section{REFERÊNCIAS}

AFRICAN COMISSION ON HUMAN AND PEOPLE'S RIGHTS. African Charter on Human and Peoples' Rights (ACHPR), 1981.Disponível em: <http://achpr.org/ english/_info/charter_en.html>. Acesso em: 23 fev. 2012.

AFRICAN COMISSION ON HUMAN AND PEOPLE'S RIGHTS.Protocol to the African Charter on Human and Peoples' Rights on the Rights of Women in Africa, 2003. Disponível em: <http://achpr.org/english/_info/women_en.html>. Acesso em: 8 dez. 2010.

AMPOFO, Adomako. Gender inequalities, Power in Unions, and Reproductive Decision Making in Ghana. PhD dissertation, Vanderbilt University, Nashville, TN. (unpublished).

ANDREWS, Lori B. How is Technology changing the Meaning of Motherhood for Western Women. In: WIDDOWS, Heather; IDIAKEZ, Itziar; CIRION, Aitziber. (eds). Women's reproducitve rights. New York: Palgrave Macmillan, 2006.

BANDA, Fareda. Blazing a Trail: The African Protocol on Women's Rights Comesinto Force. Journal of African Law, v.50, n. 1. p. 72-84, 2006.

BEIJING Declaration and Platform for Action. United Nations Fourth World Conference on Women, Organização das Nações Unidas, 1995. Disponível em: <http://www.un.org/womenwatch/daw/beijing/pdf/Beijing\%20full\%20report\%20E. pdf >. Acesso em: 20 fev. 2012.

BEVERIDGE, Fiona; MULLALLY, Siobhan, International Human Rights and Body Politics.In: BRIDGEMAN, J.; MILLNS, Susan. (eds.). Law and body politics: regulating the female body. v. 240. London: Dartmouth Publishing Co. Limited, 1995.

BLEDSOE, Caroline. Constructing Natural Fertility: The Use of Western Contraceptive Technologies in Rural Gambia. Population Development Review, n. 20 , p. 81-113, 2000.

BREMS, Eva. Protecting the Human Rights of Women. In: LYONS, Gene M.; MAYALL, James. (eds.). International human rights in the twenty-first century: protecting the rights of groups. Oxford: Rowman\&Littlefield Publishers Inc., 2003.

COBBAH, Josiah A. M.African Values and the Human Rights Debate: an African Perspective. Human Rights Quarterly, v. 9, n. 3, p. 309-331, 1987.

CORREA, Sonia. From Reproductive Health to Sexual Rights: Achievements and Future Challenges. Reproductive Rights Matters, 1997. Série 10.

DEROSE, Laurie; DODOO, Nu-Amoo; PATIL, Vrushali. Fertility Desires and Perceptions of Power in Reproductive Conflict in Ghana. Gender Society, v. 16,p. 53, 2002. 
DIXON-MUELLER, Ruth. Population policy and women's rights, transforming reproductive choice. Westport: Praeger, 1993.

DOUGLAS, Gillian. Law, fertility and reproduction. London: Sweet and Maxwell,1991.

DONNELLY, Jack. Human Rights and Human Dignity: An Analytic Critique of Nonwestern Conceptions of Human Rights. American Political Science Review, v. 76, n.2, june, p. 303-316, 1982. Disponível em:< http://pt.scribd.com/doc/62712826/ An-Analytic-Critique-of-Non-Western-Conceptions-of-Human-Rights>. Acesso em: 23 fev.2012.

FACTORS affecting contraceptive use in Sub-Saharan Africa. Disponível em: $<$ http://www.nap.edu/catalog.php?record_id=2209>.

GAWAYA, Rose; SEMAFUMU MUKASA, Rosemary. The African Women's Protocol: A New Dimension for Women's Rights in Africa. Gender and Development, v. 13, n. 3. p. 42-50, 2005.

HELLUM, Anne. Women's human rights and legal pluralism in Africa: mixed norms and identities in infertility management in Zimbabwe. Tano: Mond Books, 1999.

INTERNATIONAL Conference on Population and Development (ICPD).Cairo: Organização das Nações Unidas, 1994. Disponível em: <http://web.unfpa.org/ icpd/icpd-programme.cfm>. Acesso em: 15 mar. 1012.

INTERNATIONAL Covenant on Civil and Political Rights (ICCPR). Organização das Nações Unidas, 1966.

INTERNATIONAL Covenanton Economic, Social and Cultural Rights (ICESCR). Organização das Nações Unidas, 1966. Disponível em: <http://www2.ohchr.org/ english/law/cescr.htm>. Acesso em: 20 fev. 2012.

THE INTERNATIONAL Guidelines on HIV/AIDS and Human Rights.Disponível em: <http://data.unaids.org/Publications/IRC-pub07/jc1252-internguidelines_ en.pdf>. Acesso em: 20 fev. 2012.

KAFUI, Adjamagbo-Johnson. The entry into force of the Protocol on the Rights of Women in Africa: A Challenge for Africa and Women. Pambazuka News, n. 162, June 24, 2004.

KEMP, Karoline. General situation of women in Africa.In: MUSA, Roselynn; MOHAMMED, Faiza; MANJI, Firoze. Breathing life into the african union protocol on women's rights in Africa. 3, [s. I.]: FAHAMU, 2006.

KIMUNA, Sitawa; ADAMCHAK, Donald. Gender relations: Husband-Wife Fertility and Family Planning Decisions in Kenya. Journal of Biosociology Science, v. 33, p. 13-23, 2001.

KUPONIYI, Francis; ALADE, O. A. Gender Dynamics and Reproduction Decision making among rural families in Orire Local Government Area of Oyo State, Nigeria. Journal of Social Science, v. 15, n. 2, p. 101-104, 2007. 
LARA, Knudsen. Reproductive rights in a global context, South Africa, Uganda, Peru, Denmark, United States, Vietnam, Jordan. [s. I.]: Vanderbilt University Press, 2006.

MBAYE, Keb. International Commission of Jurists, Human and Peoples Rights in Africa and the African Charter. Geneva: International Commission of Jurists, 1986.

MBITI, John S. African religions and philosophy. 141, New York: Praeger, 1970. MCLEAN, Sheila. Women, Rights and Reproduction. In: MCLEAN, Sheila (ed.).Legal Issues in Reproduction. London: Dartmouth England, 1990.

MILLER, Alice. Sexuality, violence against women, and human rights: women make demands and ladies get protection. Health and Human Rights: an International Journal, v. 7, n.2, p. 16-46, 2004. Disponível em: <http://www. hhrjournal.org/archives-pdf/4065347.pdf.bannered.pdf>. Acesso em: 20 fev. 2012.

MUMBI, Machera. Opening a Can of Worms: A Debate on Female Sexuality inthe Lecture Theatre. In: ARNFRED, S. (ed.). Rethinking sexualities in Africa. 154, Lund: Nordic Africa Institute, 2004.

MUKASA, Sarah. Domesticating the Protocol. In: MUSA, Roselynn; MOHAMMED, Faiza; MANJI, Firoze (eds.). Breathing life into the African Union Protocol on Women's Rights in Africa 28, [s. I.]: FAHAMU, 2006.

ODINKALU, Chidi Anselm. Back to the future: The imperative of prioritizing for the protection of human rights in Africa. Journal of African Law, v. 47, n.1, p.1-37, 1997.

OKERE, Okinna Bertna. The Protection of Human Rights in Africa and the African Charter on Human and Peoples Rights: A Comparative analysis with the European and American systems. Human Rights Quarterly, v.6, p.141-148, 1984.

OVERALL, Christine. Human reproduciton: principles, practices and policies. Toronto: Oxford University Press, 1993.

PHILLIPS, Oliver. A Brief Introduction to the Relationship between Sexuality and Rights. Georgia Journal Of International And Comparative Law, v. 33, n.451, winter, 2005.

PROCLAMATION of Tehran Final Act of the International Conference on Human Rights. Teerã: Organização das Nações Unidas, 1968.

RAO, Radhika. Constitutional Misconceptions. Michigan Law Review, v.93, 1995.

RUNGANGA, Agnes; SUNDBY, Johanne; AGGLETON, Peter. Culture, Identity and Reproductive Failure in Zimbabwe. Sexualities, v. 4, 2001.

SMART, Carol. Feminism and the power of law. London: Routledge, 1989.

SSENYONJO, Manisuli. Culture and the Human Rights of Women in Africa: Between Light and Shadow. Journal of African Law, v. 51, n. 1, p. 39-67,2007. 
TAMALE, Sylvia. Gender Trauma in Africa: Enhancing Women's Links to Resources. Journal of African Law, v. 48, n. 1, 2004.

TAMALE, Sylvia. The Right to Culture and the Culture of Rights: A Critical Perspective on Women's Sexual Rights in Africa. Feminist Legal Studies, v. 16, p. 47-69, 2008.

THE DIVISION for the Advancement of Women. Disponível em: <http://www. un.org/womenwatch/daw/cedaw>. Acesso em: 20 dez. 2006.

THE INTERNATIONAL Guidelines on HIV/AIDS and Human Rights. Disponível em: $<$ http://data.unaids.org/Publications/IRC-pub07/jc1252-internguidelines_ en.pdf>. Acesso em: 20 fev. 2012.

UNIVERSAL Declarationon Human Rights (UDHR). Organização das Nações Unidas, 1948. Disponível em:<http://www.un.org/en/documents/udhr/>. Acesso em: 20 fev. 2012.

WANDIA, Mary. Rights of Women in Africa: Launch of Petition to the African Union. Pambazuka News, n. 159, June 3, 2004.

WOMEN'S Health and Information Centre.Disponível em: <http://www. nchealthywomen.org>.

WORLD HEALTH ORGANIZATION.Maternal Mortality Rate: Tabulation of Available Information. 2nd Ed. Geneva: WHO, 1986.

WORLD HEALTH ORGANIZATION. Report. Disponível em: <www.who.org>

WORLD HEALTH ORGANIZATION.Sexual and Reproductive Health Research Priorities for WHO for the period 1998-2003, 1997.

YAW, Oheneba-Sakyi, et al. Female autonomy, decision making and demographic behaviour among couples in Ghana. New York: Potsdam, 1995.

YAW, Oheneba-Sakyi; TAKYI, Baffour. Effects of Couples Characteristics on Contraceptive use in Sub-Saharan Africa: The Ghanaian example. Journal of Biosociology Science, v. 29, p. 33-49, 1997. 